\title{
Medical Nutrition Therapy in Hospitalized Patients With SARS-CoV-2 (COVID-19) Infection in a Non-critical Care Setting: Knowledge in Progress
}

\author{
Enrique Cervantes-Pérez ${ }^{1,2}$ (1) - Gabino Cervantes-Guevara ${ }^{2,3} \cdot$ Martha C. Martínez-Soto Holguín ${ }^{1} \cdot$ \\ Lorena A. Cervantes-Pérez ${ }^{4}$. Gabino Cervantes-Pérez ${ }^{3}$. Guillermo Alonso Cervantes-Cardona ${ }^{5}$. \\ Alejandro González-Ojeda ${ }^{6} \cdot$ Clotilde Fuentes-Orozco $^{6} \cdot$ Sol Ramírez-Ochoa $^{7}$
}

Accepted: 16 October 2020 / Published online: 30 October 2020

(C) Springer Science+Business Media, LLC, part of Springer Nature 2020

\begin{abstract}
Purpose of Review As of 13 September 2020, almost 28 million confirmed cases of COVID-19 including more than 920,000 deaths have been reported to the World Health Organization. The SARS-CoV-2 pandemic represents a potential threat to patients and healthcare systems worldwide. Patients with the worst outcomes and higher mortality are reported to include older adults, polymorbid individuals, and malnourished people in general. The purpose of this review is to provide concise guidance for the nutritional management of individuals with COVID-19 based on the current literature and focused on those in the non-ICU setting or with an older age and polymorbidity, which are independently associated with malnutrition and its negative impact on mortality.

Recent Findings Prolonged hospital stays are reported to be required for individuals with COVID-19, and longer acute setting stays may directly worsen or cause malnutrition, with severe loss of skeletal muscle mass and function, which may lead to poor quality of life and additional morbidity. Nutritional therapy is among the mainstay of therapeutic principles and one of the core contents of comprehensive treatment measures.

Summary The current COVID-19 pandemic is unprecedented. The prevention, diagnosis, and treatment of malnutrition should therefore be routinely included in the management of individuals with COVID-19.
\end{abstract}

Keywords SARS-CoV-2 $\cdot$ Nutrition therapy $\cdot$ Malnutrition $\cdot$ Oral nutritional supplements $\cdot$ Immunonutrition

\section{Introduction}

Numerous cases of pneumonia caused by a new virus, severe acute respiratory syndrome coronavirus 2 (SARS-CoV-2), were initially reported in Wuhan, China, at the end of December 2019. Since then, several thousand cases have been reported in China, and the disease has spread worldwide. As of 14 September 2020, almost 29 million confirmed cases of
Enrique Cervantes-Pérez

enrique.cervantes@ academico.udg.mx

1 Department of Clinical Nutrition, Instituto Nacional de Ciencias Médicas y Nutrición Salvador Zubirán, Vasco de Quiroga, 15, Col. Belisario Domínguez Sección XVI, Del. Tlalpan. CP, 14080 Mexico City, Mexico

2 Department of Welfare and Sustainable Development, Centro Universitario del Norte, Universidad de Guadalajara,

Colotlán, Jalisco, Mexico

3 Department of Gastroenterology, Hospital Civil de Guadalajara "Fray Antonio Alcalde", Guadalajara, Jalisco, Mexico
4 Bone Marrow Transplantation Unit, Instituto Nacional de Cancerología, Mexico City, Mexico

5 Department of Philosophical, Methodological and Instrumental Disciplines, Centro Universitario de Ciencias de la Salud, Universidad de Guadalajara, Guadalajara, Jalisco, Mexico

6 Biomedical Research Unit 02, Specialties Hospital of the Western National Medical Center, Mexican Institute of Social Security, Guadalajara, Mexico

Department of Internal Medicine, Hospital Civil de Guadalajara "Fray Antonio Alcalde", Guadalajara, Jalisco, Mexico 
COVID-19 including more than 920,000 deaths have been reported to World Health Organization [1]. Although many comparisons to other coronavirus epidemics have been made, the potential impact of this coronavirus remains unknown. The purpose of this review is to summarize what is known about SARS-CoV-2 infection and provide possible and potential nutritional interventions on novel coronaviruses for clinicians.

Coronaviruses are widespread mainly by birds and mammals. The widest varieties of genotypes infect bats, but two subtypes infect humans: alpha and beta coronaviruses [2]. Beta coronaviruses include severe acute respiratory syndrome coronavirus (SARS-CoV), Middle East respiratory syndrome coronavirus (MERS-CoV), and the coronavirus variant that causes COVID-19, all of which are members of the Coronaviridae family of the order Nidovirales [3]. Currently, there is no registered treatment or vaccine for the disease. Given the absence of specific treatment for this novel infection, there is a growing need to find alternatives and potential solutions to prevent and control the infection to improve both short- and long-term prognosis.

\section{Screening and Assessment of Malnutrition}

Older adults and polymorbid individuals suffering from chronic and acute disease conditions are at increased risk for poor outcomes and higher mortality following infection with the COVID-19-causing virus. Furthermore, identification of risk and the presence of malnutrition should be an early and routine step in the general evaluation of all patients.

Some scores, such as the NRS-2002 and MUST, have long been used in hospitalized patients or in specific disease scenarios for malnutrition risk screening. Other tools include the Mini Nutritional Assessment criteria, the Subjective Global Assessment criteria, and the NUTRIC score criteria for critically ill patients $[4,5]$.

Recently, the GLIM (Global Leadership Initiative on Malnutrition) criteria proposed a two-step approach for malnutrition diagnosis by identifying patients at risk using validated screening tools (MUST, NRS-2002) with the possibility of grading the severity of malnutrition [6].

Because poorer outcomes and higher mortality are reported in patients at risk for malnutrition, these considerations seem to be applicable to hospitalized patients at risk for COVID-19 infection. Nutritional status and preventing or treating malnutrition are the cornerstones to reducing complications and aiding patients who might be infected in the future. In addition, some gastrointestinal symptoms of SARS-CoV-2 infection, including nausea, vomiting, and diarrhea, might compromise food intake and nutrient absorption [7,8].

\section{Macronutrients-Energy Needs}

Based on the Spanish influenza pandemic of 1918-1919 causing acute illness in $30 \%$ of the world's population and 40 million deaths and, more recently, the 2009 influenza pandemic, all these retrospective analyses of available data revealed that the disease severity depended on viral and host factors. Some of these included cellular and humoral immune responses and nutritional and genetic aspects. In addition, a current challenge is not only to take care of those affected by undernutrition but also people living with obesity. Some viral responses, such as virus-specific $\mathrm{CD} 8+\mathrm{T}$ cells, have been described in obese patients [9].

The diet counseling process in SARS-CoV-2-infected patients could be performed using electronic devices when possible to limit the exposure of the clinician. Patients at nutritional risk should receive nutritional support as soon as possible, particularly increasing protein intake by consuming oral nutrition supplements (ONSs) [9]. If available, indirect calorimetry must be used to assess energy needs. Some other alternatives are prediction equations or weight-based formulae. For polymorbid patients aged $>65$ years, the consumption of a total of $27 \mathrm{kcal} / \mathrm{kg}$ body weight per day is recommended. In the case of severely underweight polymorbid patients, $30 \mathrm{kcal} /$ $\mathrm{kg}$ body weight per day should be considered. A goal of $30 \mathrm{kcal} / \mathrm{kg}$ body weight should be slowly achieved to avoid refeeding syndrome $[4,10]$.

Protein needs are estimated according to age, nutritional status, physical activity level, disease status, and tolerance. Geriatric patients should receive $1 \mathrm{~g}$ protein per kg body weight/day and $>1 \mathrm{~g}$ per $\mathrm{kg}$ body weight/day in polymorbid patients to prevent body weight loss and hospital readmission and reduce the risk of complications [4, 10]. Regarding the nonprotein calorie (fat and carbohydrate) ratio, in participants with no acute respiratory distress syndrome, a ratio of approximately 30:70 is recommended. Patients who are not at risk for malnutrition should maintain adequate protein $(1.5 \mathrm{~g} / \mathrm{d})$ and nonprotein caloric (25-30 kcal/d) intake [11•] (Fig. 1).

\section{Micronutrients}

\section{Trace Elements}

Trace elements are fundamental for the correct functioning of our bodies, and they are especially important in disease states. There are no specific recommendations about how to supplement trace elements in individuals with COVID-19, but here is some evidence about the benefits of these minerals and their importance in the proper functioning of the body; these minerals should be supplemented in case of deficiency [12••]. Key dietary components such as vitamins $\mathrm{A}, \mathrm{C}, \mathrm{D}, \mathrm{E}$, iron, zinc, selenium, and copper have well-established 
Fig. 1 Nutritional recommendations in hospitalized individuals with COVID-19 in a non-critical care setting. Nutritional goals should be cautiously and slowly achieved, as this is a population at high risk of refeeding syndrome. GLIM: Global Leadership Initiative on Malnutrition; MST: Malnutrition Screening Tool; MUST: Malnutrition Universal Screening Tool

\author{
High Nutrition Risk \\ - Requiring Enteral or Parenteral Nutrition \\ - Malnutrition or suspected malnutrition (GLIM, MST, MUST) \\ - Body Mass Index $<18.5 \mathrm{~kg} / \mathrm{m} 2$ \\ - Recent weight loss $\geq 10 \%$ \\ - Anaphylactic food allergy \\ - Considered at high risk of refeeding
}

Nutrition Associated Problem With COVID-19
Nausea, vomiting, diarrhea, abdominal pain and severe fatigue which impair food
intake and absorption
Side effects of Antiviral drugs (such as Chloroquine)

\footnotetext{
Treatment of malnutrition in individuals infected with COVID-19

- Energy needs:

- For polymorbid patients aged $>65$ years: $27 \mathrm{kcal} / \mathrm{kgBW} / \mathrm{day}$

- For severely underweight polymorbid patients: $30 \mathrm{kcal} / \mathrm{kgBW} /$ day

- Protein needs:

- $1 \mathrm{~g} / \mathrm{kgBW} /$ day in older persons

- $>1 \mathrm{~g} / \mathrm{kgBW} /$ day in polymorbid medical inpatients in order to prevent body weight loss, reduce the risk of complications and hospital readmission
}

- Energy and protein enriched diet

\title{
Oral feeding
}

- Soft/liquid diet is preferred

- When it is insufficient to meet requirement, oral nutritional supplement (ONS) should be used to provide at least $400 \mathrm{kcal} / \mathrm{day}$ including $30 \mathrm{~g}$ or more of protein/day and shall be continued for atleast one month.

Enteral Nutrition Administration
- If oral intake is expected to be impossible for more than three days or expected to be
$<50 \%$ of energy requirements for more than one week.
- Infusion of formula into the stomach via $10-12 \mathrm{Fr}$ feeding nasogastric tube.
- Initiate with low dose $10-20 \mathrm{ml} / \mathrm{h}$ of hypocaloric or trophic, advancing to full dose
enteral nutrition slowly over the first week.

Parenteral Nutrition
$\begin{aligned} & \text { - Early parenteral nutrition should be initiated as soon as possible in the high-risk } \\ & \text { patient for whom early gastric enteral nutrition is not feasible or not achieve target. }\end{aligned}$
Timing of Nutrition Delivery
- Start early during hospitalization within $24-48$ hours, especially for older and
polymorbid patients.

immunomodulatory effects, with benefits in infectious disease. Some of these nutrients have also been shown to have a potential role in the management of COVID-19 [13].

\section{Selenium}

Selenium is an essential trace element for mammalian redox biology [14]. The nutritional status of the host plays a very important role in the defense against infectious diseases. Nutritional deficiency impacts not only the immune response but also the viral pathogen itself. Dietary selenium deficiency, which causes oxidative stress in the host, can alter a viral genome so that a normally benign or mildly pathogenic virus can become highly virulent in the deficient host under oxidative stress conditions [15]. This is because selenium could assist a group of enzymes that, in concert with vitamin E, work to prevent the formation of free radicals and prevent oxidative damage to cells and tissues [16].

\section{Zinc}

Zinc is a trace dietary mineral and is important for the maintenance and development of immune cells of both the innate and adaptive immune systems [17]. Zinc has the potential to increase the cytotoxic activity of NK cells, which can attack cells that exhibit abnormal or unusual proteins in the plasma membrane. When NK cells kill infected cells, the microorganisms inside are released and destroyed through phagocytosis by neutrophils and macrophages, which migrate to infected areas. The zinc also acts as an anti-inflammatory agent, 
maintaining immune tolerance as it induces the development of regulatory $\mathrm{T}$ cells and mitigates the development of proinflammatory Th17 and Th9 cells, besides being involved in antibody production, particularly IgG. Zinc deficiency is very common, particularly within the elderly population, and there are difficulties in the diagnosis because of the lack of clinical signs and reliable biochemical indicators, as well as the absence of a specific and reliable biomarker of zinc status [18]. Increased intracellular $\mathrm{Zn} 2+$ concentrations are known to efficiently impair the replication of several RNA viruses. A study in 2010 reported that coronavirus replication can be inhibited by increased $\mathrm{Zn} 2+$ levels. The concentration of $2 \mathrm{uM} \mathrm{Zn2}+$ inhibited the replication of SARS-coronavirus (SARS-CoV) in cell culture [19].

\section{Iron}

Iron is a nutrient with diverse implications in COVID-19. First, it is well-known the importance of iron for the correct functioning of the immune system. However, it is also wellestablished that iron-containing enzymes are essential for the completion of virus replication process, particularly coronaviruses. Thus, it has been pointed out that iron chelation could be an alternative adjuvant strategy to treat individuals with COVID-19, via manipulation of key iron regulators (still needs further research), venous injection, or oral administration of iron chelators [20].

Iron participates in several immune processes and is an essential component for some enzymes involved in crucial activities of immune cells. Due to its structure, iron also plays an important role as a mediator of oxidative stress situations (acting as a redox catalyst) and exerts powerful antimicrobial effects by forming highly toxic hydroxyl radicals for infection agents. Therefore, deficient or suboptimal levels of iron are associated with decreased killer efficiency of NK cells and lymphocytes as well as with compromised cytokine production $[21,22]$.

Therefore, both iron uptake disturbances and metabolism are implicated in virulence of airway hospital-acquired infection and chronic respiratory infections. In contrast, excessive iron levels can generate harmful cellular toxicity, so their serum levels must be well regulated [23]. In the case of COVID19 , iron metabolism is clearly disrupted in SARS-CoV-2infected patients, especially in patients hardest hit by the disease; consequently, anemia or hyperferritinemia are typical manifestations of hospitalized individuals with COVID-19. Therefore, optimal iron status may be crucial for better disease prognosis. Populations with lower iron status could be more prone to suffer a mild to severe (or critical) symptomatology of COVID-19 and the fact of monitoring patient iron levels has been proposed as a potential early marker to predict COVID-19 severity and mortality [23, 24].

\section{Vitamins}

It is now known that patients with nutritional deficiencies are at the highest risk for ventilatory complications. Patients with malnutrition should ensure sufficient supplementation with vitamins and minerals. Part of the general treatment for viral infections is vitamin supplementation to improve the outcome of the disease [25].

\section{Vitamin A}

Many host defenses depend on the adequate supply of this vitamin, and it has been reported that vitamin A supplementation reduces the morbidity and mortality of different infectious diseases. It has also been reported that supplementation with vitamin A offers some protection against the complications of other life-threatening infections [26-28]. The mechanism by which vitamin A and retinoids inhibit measles replication is upregulating elements of the innate immune response in uninfected bystander cells, making them refractory to a productive infection during subsequent rounds of viral replication [29]. Vitamin A could be a promising option for the treatment of this novel coronavirus.

\section{B Vitamins}

Each vitamin B has its special functions; vitamin B2 (riboflavin) plays a role in the energy metabolism of all cells. Keil et al. reported that vitamin B2 and UV light effectively reduced the titer of MERS-CoV in human plasma products [30]. Vitamin B3 significantly inhibited neutrophil infiltration into the lungs with a strong anti-inflammatory effect during ventilator-induced lung injury when tested against Staphylococcus aureus infections [31, 32]. Vitamin B6 is needed for protein metabolism and participates in over 100 reactions in body tissues. As a shortage of $\mathrm{B}$ vitamins may weaken the host immune response, B vitamins could be supplemented to SARS-CoV-2-infected patients to enhance their immune system.

\section{Vitamin C}

Vitamin C is known as an essential antioxidant and enzymatic co-factor for physiological reactions, such as hormone production, collagen synthesis, and immune potentiation, also improves vasopressor synthesis, improves endovascular function, and exerts epigenetic immunologic modifications [33]. Vitamin C may also function as a weak antihistamine agent to provide relief from flu-like symptoms such as sneezing, a runny or stuffy nose, and swollen sinuses [34]. Humans are unable to synthesize vitamin $C$; therefore, they must acquire vitamin $\mathrm{C}$ from dietary sources. The therapeutic use of vitamin $\mathrm{C}$ to prevent inflammatory hyperactivation in myeloid and 
lymphoid cells has been explored. High doses of vitamin $\mathrm{C}$ act as a prooxidant for immune cells but as an antioxidant for lung epithelial cells, though there is not enough evidence to suggest its routine use $[35,36]$. Recently registered on clincialtrials. gov (Identifier: NCT04264533), a new clinical trial to investigate vitamin $\mathrm{C}$ infusion for the treatment of severe 2019-nCoV-infected pneumonia began in Wuhan, China. This is one of the first RCTs to test the effects of IV vitamin $\mathrm{C}$ in patients infected with this virus. In this trial, the investigators will treat 140 patients with a placebo control or intravenous vitamin $\mathrm{C}$ at a dose of $24 \mathrm{~g} /$ day for 7 days. They will assess requirements for mechanical ventilation and vasopressor drugs, organ failure scores, ICU length of stay, and 28-day mortality [37].

\section{Vitamin D}

In addition to its role in maintaining bone integrity, vitamin $\mathrm{D}$ also stimulates the maturation of many cells, including immune cells [38]. Several reviews have considered the way in which vitamin $\mathrm{D}$ reduces the risk of microbial infection and death, and those mechanisms can be grouped into three categories: physical barrier, cellular natural immunity, and adaptive immunity. Vitamin D helps maintain tight cell junctions, gap junctions, and adherens junctions. Many healthy adults have been reported to have low levels of vitamin D, mostly at the end of the winter season [39]. The association of vitamin D deficiency with respiratory tract infections and lung injury has been widely reported. Indeed, the usage of vitamin D agonists has shown effectiveness ameliorating the aforementioned conditions. The striking overlap between risk factors for severe COVID-19 and vitamin D deficiency, including obesity, older age, and Black or Asian ethnic origin, has led some researchers to hypothesize that vitamin D supplementation could hold promise as a preventive or therapeutic agent for COVID-19. There are good reasons to postulate that vitamin $\mathrm{D}$ favorably modulates host responses to severe acute respiratory syndrome coronavirus 2 (SARS-CoV-2), both in the early viremic and later hyperinflammatory phases of COVID-19 [40]. Furthermore, previous investigations have demonstrated that high-dose supplementation of vitamin D $(250,000$ $500,000 \mathrm{IU} /$ day) is safe and effective in improving the health status of mechanically ventilated critically ill patients (enhancing the capacity of blood for oxygen transport and increasing hemoglobin levels), which resulted in shorter hospital stays [20].

\section{Vitamin E}

Vitamin E is a lipid-soluble vitamin that plays an important role in reducing oxidative stress by binding to free radicals as an antioxidant. Vitamin $\mathrm{E}$ is a major fat-soluble antioxidant that scavenges peroxyl radicals and terminates the oxidation of polyunsaturated fatty acids (PUFAs). Dietary interventions with vitamin $\mathrm{E}$ at supplemental levels have been shown to enhance cell-mediated and humoral immune responses in various species of animals [41]. Increased lymphocyte proliferation, immunoglobulin levels, antibody responses, natural killer (NK) cell activity, and interleukin (IL)-2 production have been reported with vitamin E supplementation [42, 43].

In humans, the effects of vitamin $\mathrm{E}$ on the natural incidence of infectious diseases have been determined in several studies. Many studies have provided evidence that the immunostimulatory effects of vitamin E confer improved resistance to infections. However, the magnitudes of the effects were rather small, and in some studies, positive effects were only observed in subgroups of participants. A recent study found a lower incidence of pneumonia among participants taking $50 \mathrm{mg} /$ day of vitamin $\mathrm{E}$ for a median of 6 years [44].

\section{Polyunsaturated Fatty Acids}

Long-chain polyunsaturated fatty acids (PUFAs) are important mediators of inflammation and adaptive immune responses. Omega-3 and omega-6 PUFAs predominantly promote anti-inflammatory and proinflammatory effects. They are precursors of resolvins/protectins and prostaglandins/leukotrienes, respectively. It has been shown that protectin D1, an omega-3 PUFA-derived lipid mediator, could markedly attenuate influenza virus replication via the RNA export machinery. Omega-3 PUFAs, including protectin D1, could be considered a potential intervention for COVID-19 [12••].

\section{Immunonutrition and COVID-19}

T cells, B cells, the complement system, and phagocytes compose the immune system. All these are the primary defense barriers against infections, and any weaknesses could be detrimental to the host, and malnutrition can result in weaknesses of these defensive barriers. It is also known that healthy immune systems are one way of defending against viral infections [45]. Numerous scientific papers have been published explaining the role of nutrition in the immune system describing the declining $\mathrm{T}$ cell function attributed to thymic involution and subsequent reduced output of naïve $\mathrm{T}$ cells [46], aging-associated inflammation [47], and poor micronutrient status - a bidirectional relationship between infection/ immunity and nutrition, whereby changes in one of these components can impact the other [48]. Gombart et al. identified that potential synergistic relationships of micronutrients are required to meet the complex needs of the immune system, including relationships among vitamins $\mathrm{A}, \mathrm{D}, \mathrm{C}, \mathrm{E}, \mathrm{B}_{6}$, and $\mathrm{B}_{12}$; folate; copper; iron; zinc; and selenium, but the largest body of evidence comes from vitamins $\mathrm{C}$ and $\mathrm{D}$ and zinc [49••]. 


\section{Conclusions}

According to previous SARS and MERS treatments, some general treatments, including nutritional interventions, are very important to enhance the host immune response. Every effort should be made to avoid or limit underfeeding in individuals with COVID-19, and proper nutritional strategies should ensure adequate support for hospitalized patients to reduce or prevent consequences in malnourished populations. Moreover, given the rapid transmission of COVID-19, clinicians are working against the clock to find potential possible solutions. Unfortunately, rigorous trials are currently lacking, and most of what we know is based on observational evidence or previous studies conducted in other populations with infectious diseases.

Author Contributions All authors read and approved the final version of the paper. The overall idea was developed by E.C.P and G.C.G. Clinical perspective was provided by L.A.C.P., G.C.P., and S.R.O; nutritional perspective was provided by M.M.S.H and G.A.C.C.; and A.G.O and C.F.O contributed to the design of the review. The article was crafted by E.C.P and M.M.S.H. The final draft was edited by all authors.

\section{Compliance with Ethical Standards}

Conflict of Interest The authors have no relevant interests to declare.

Human and Animal Rights and Informed Consent This article does not contain any studies with human oranimal subjects performed by any of the authors.

\section{References}

Papers of particular interest, published recently, have been highlighted as:

- Of importance

•- Of major importance

1. WHO coronavirus disease (COVID-19) dashboard. Geneva: World Health Organization, 2020. Available online: https://covid19.who. int/ [Accessed 14 Sept 2020].

2. Banerjee A, Kulcsar K, Misra V, Frieman M, Mossman K. Bats and coronaviruses. Viruses. 2019;11:41.

3. Memish ZA, Perlman S, Van Kerkhove MD, Zumla A. Middle East respiratory syndrome. Lancet. 2020;395:1063-77.

4. Volkert D, Beck AM, Cederholm T, Cruz-Jentoft A, Goisser S, Hooper L, et al. ESPEN guideline on clinical nutrition and hydration in geriatrics. Clin Nutr. 2019;38:10-47.

5. Cederholm T, Barazzoni R, Austin P, Ballmer P, Biolo G, Bischoff $\mathrm{SC}$, et al. ESPEN guidelines on definitions and terminology of clinical nutrition. Clin Nutr. 2017;36:49-64.

6. Cederholm T, Jensen GL, Correia MITD, Gonzalez MC, Fukushima R, Higashiguchi T, et al. GLIM criteria for the diagnosis of malnutrition - a consensus report from the global clinical nutrition community. Clin Nutr. 2019;38:1-9.
7. Gu J, Han B, Wang J. COVID-19: gastrointestinal manifestations and potential fecal-oral transmission. Gastroenterology. 2020;158(6):1518-9.

8. Chen N, Zhou M, Dong X, Qu J, Gong F, Han Y, et al. Epidemiological and clinical characteristics of 99 cases of 2019 novel coronavirus pneumonia in Wuhan, China: a descriptive study. Lancet. 2020;395:507-13.

9. Short KR, Kedzierska K, van de Sandt CE. Back to the future: lessons learned from the 1918 influenza pandemic. Front Cell Infect Microbiol. 2018;8:343.

10. Gomes F, Schuetz P, Bounoure L, Austin P, Ballesteros-Pomar M, Cederholm T, et al. ESPEN guidelines on nutritional support for polymorbid internal medicine patients. Clin Nutr. 2018;37(1):33653.

11. Jin YH, Cai L, Cheng ZS, Cheng H, Deng T, Fan YP, et al. A rapid advice guideline for the diagnosis and treatment of 2019 novel coronavirus (2019-nCoV) infected pneumonia (standard version). Mil Med Res. 2020;7(1):4. https://doi.org/10.1186/s40779-0200233-6 This guideline established that the patient should be given supportive treatment to ensure sufficient energy intake and balance for water, electrolytes, acid-base levels, and other internal environment factors (Strong recommendation).

12.• Zhang L, Liu Y. Potential interventions for novel coronavirus in China: a systematic review. J Med Virol. 2020;92:479-90. https:// doi.org/10.1002/jmv. 25707 This review summarized all the potential interventions for COVID-19 infection according to previous treatments of SARS and MERS. It suggested that all the potential interventions be implemented to control the emerging COVID-19 if the infection is uncontrollable and proposed to verify the nutritional status of COVID-19-infected patients before the administration of general treatments.

13. Shakoor H, Feehan J, Al Dhaheri AS, et al. Immune-boosting role of vitamins D, C, E, zinc, selenium and omega-3 fatty acids: could they help against COVID-19? Maturitas. 2021;143:1-9. https://doi. org/10.1016/j.maturitas.2020.08.003.

14. Rayman MP. Selenium and human health. Lancet. 2012;379:125668 .

15. Guillin OM, Vindry C, Ohlmann T, Chavatte L. Selenium, selenoproteins and viral infection. Nutrients. 2019;11:2101.

16. Harthill M. Review: micronutrient selenium deficiency influences evolution of some viral infectious diseases. Biol Trace Elem Res. 2011;143:1325-36.

17. Maares M, Haase H. Zinc and immunity: an essential interrelation. Arch Biochem Biophys. 2016;611:58-65.

18. de Almeida Brasiel PG. The key role of zinc in elderly immunity: a possible approach in the COVID-19 crisis. Clin Nutr ESPEN 2020;38:65-6. https://doi.org/10.1016/j.clnesp.2020.06.003.

19. te Velthuis AJW, van den Worm SHE, Sims AC, Baric RS, Snijder EJ, van Hemert MJ. $\mathrm{Zn}(2+)$ inhibits coronavirus and arterivirus RNA polymerase activity in vitro and zinc ionophores block the replication of these viruses in cell culture. PLoS Pathog. 2010;6: e1001176.

20. Fernández-Quintela A, Milton-Laskibar I, Trepiana J, GómezZorita S, Kajarabille N, Léniz A, et al. Key aspects in nutritional management of COVID-19 patients. J Clin Med. 2020;9(8):E2589. https://doi.org/10.3390/jcm9082589.

21. Strahle WC, Handley JC. Prediction of combustion induced vibration in rocket motors. Cell Host Microbe. 1978;13:509-19.

22. Agoro R, Taleb M, Quesniaux VFJ, Mura C. Cell iron status influences macrophage polarization. PLoS One. 2018;13(5):e0196921. https://doi.org/10.1371/journal.pone.0196921.

23. Galmés S, Serra F, Palou A. Current state of evidence: influence of nutritional and nutrigenetic factors on immunity in the COVID-19 pandemic framework. Nutrients. 2020;12(9):E2738. https://doi.org/ $10.3390 /$ nu12092738 
24. Zhao K, Huang J, Dai D, Feng Y, Liu L, Nie S. Serum Iron Level as a potential predictor of coronavirus disease 2019 severity and mortality: a retrospective study. Open Forum Infect Dis. 2020;7(7): ofaa250. https://doi.org/10.1093/ofid/ofaa250.

25. Barazzoni R, et al. ESPEN expert statements and practical guidance for nutritional management of individuals with SARS-CoV-2 infection. Clin Nutr. 2020. https://doi.org/10.1016/j.clnu.2020.03.022.

26. Kantoch M, Litwinska B, Szkoda M, Siennicka J. Importance of vitamin A deficiency in pathology and immunology of viral infections. Rocz Panstw Zakl Hig. 2002;53:385-92.

27. Semba RD. Vitamin A and immunity to viral, bacterial and protozoan infections. Proc Nutr Soc. 1999;58:719-27.

28. Villamor E, Mbise R, Spiegelman D, et al. Vitamin A supplements ameliorate the adverse effect of HIV - 1, malaria, and diarrheal infections on child growth. Pediatrics. 2002;109:e6.

29. Trottier C, Colombo M, Mann KK, Miller WH Jr, Ward BJ. Retinoids inhibit measles virus through a type I IFN - dependent bystander effect. FASEB J. 2009;23:3203-12.

30. Keil SD, Bowen R, Marschner S. Inactivation of Middle East respiratory syndrome coronavirus (MERS-CoV) in plasma products using a riboflavin-based and ultraviolet light-based photochemical treatment. Transfusion. 2016;56:2948-52. https://doi.org/10.1111/ trf. 13860 .

31. Kyme P, Thoennissen NH, Tseng CW, Thoennissen GB, Wolf AJ, Shimada K, et al. C/EBPepsilon mediates nicotinamide - enhanced clearance of Staphylococcus aureus in mice. J Clin Invest. 2012;122:3316-29.

32. Jones HD, Yoo J, Crother TR, Kyme P, Ben-Shlomo A, Khalafi R, et al. Nicotinamide exacerbates hypoxemia in ventilator - induced lung injury independent of neutrophil infiltration. PLoS One. 2015; 10:e0123460.

33. Ngo B, Van Riper JM, Cantley LC, et al. Targeting cancer vulnerabilities with high-dose vitamin C. Nat Rev Cancer. 2019;19:27182.

34. Field CJ, Johnson IR, Schley PD. Nutrients and their role in host resistance to infection. J Leukoc Biol. 2002;71:16-32.

35. Kashiouris MG, L'Heureux M, Cable CA, Fisher BJ, Leichtle SW, Fowler AA. The emerging role of vitamin $\mathrm{C}$ as a treatment for sepsis. Nutrients. 2020;12:292.

36. Rosa SGV, Santos WC. Clinical trials on drug repositioning for COVID-19 treatment. Rev Panam Salud Publica. 2020;44:e40. https://doi.org/10.26633/RPSP.2020.40.

37. Carr AC. A new clinical trial to test high-dose vitamin $\mathrm{C}$ in patients with COVID-19. Crit Care. 2020;24:133.
38. Tangpricha V, Pearce EN, Chen TC, Holick MF. Vitamin D insufficiency among free - living healthy young adults. Am J Med. 2002;112:659-62.

39. Calder PC, Carr AC, Gombart AF, Eggersdorfer M. Optimal nutritional status for a well-functioning immune system is an important factor to protect against viral infections. Nutrients. 2020;12:1181.

40. Martineau AR, Forouhi NG. Vitamin D for COVID-19: a case to answer? Lancet Diabetes Endocrinol. 2020;8(9):735-6. https://doi. org/10.1016/S2213-8587(20)30268-0.

41. Lee GY, Han SN. The role of vitamin E in immunity. Nutrients. 1614;2018:10

42. Moriguchi S, Kobayashi N, Kishino Y. High dietary intakes of vitamin $\mathrm{E}$ and cellular immune functions in rats. J Nutr. 1990;120:1096-102.

43. Sakai S, Moriguchi S. Long-term feeding of high vitamin E diet improves the decreased mitogen response of rat splenic lymphocytes with aging. J Nutr Sci Vitaminol. 1997;43:113-22.

44. Hemilä H. Vitamin E administration may decrease the incidence of pneumonia in elderly males. Clin Interv Aging. 2016;11:1379-85.

45. Calder PC. Feeding the immune system. Proc Nutr Soc. 2013;72: 299-309.

46. Berzins SP, Uldrich AP, Sutherland JS, Gill J, Miller JFAP, Godfrey DI, et al. Thymic regeneration: teaching an old immune system new tricks. Trends Mol Med. 2002;8:469-76.

47. Franceschi C, Garagnani P, Parini P, Giuliani C, Santoro A. Inflammaging: a new immune-metabolic viewpoint for age- related diseases. Nat Rev Endocrinol. 2018;14:576-90.

48. Maggini S, Pierre A, Calder P. Immune function and micronutrient requirements change over the life course. Nutrients. 2018;10:1531.

49.• Gombart AF, Pierre A, Maggini S. A review of micronutrients and the immune system-working in harmony to reduce the risk of infection. Nutrients. 2020;12:236 This review established that the inflammatory response bridges the gap between innate and adaptive immunity, and is regulated by vitamins $\mathrm{A}, \mathrm{C}, \mathrm{E}$, and B6, as well as iron, zinc, and copper. Adaptive immune responses encompassing cell-mediated and humoral immunity depend again on the presence of a variety of micronutrients at all stages.

Publisher's Note Springer Nature remains neutral with regard to jurisdictional claims in published maps and institutional affiliations. 